This is an electronic reprint of the original article. This reprint may differ from the original in pagination and typographic detail.

Author(s): Hakala, Ismo; Myllymäki, Mikko

Title: $\quad$ From face-to-face to blended learning using ICT

Year: $\quad 2016$

Version:

Please cite the original version:

Hakala, I., \& Myllymäki, M. (2016). From face-to-face to blended learning using ICT. In EDUCON 2016 : Proceedings of 2016 IEEE Global Engineering Education Conference (pp. 409-418). IEEE. IEEE Global Engineering Education Conference. https://doi.org/10.1109/EDUCON.2016.7474586

All material supplied via JYX is protected by copyright and other intellectual property rights, and duplication or sale of all or part of any of the repository collections is not permitted, except that material may be duplicated by you for your research use or educational purposes in electronic or print form. You must obtain permission for any other use. Electronic or print copies may not be offered, whether for sale or otherwise to anyone who is not an authorised user. 


\title{
From Face-to-Face to Blended Learning using ICT
}

\author{
Ismo Hakala, Mikko Myllymäki \\ Kokkola University Consortium Chydenius \\ University of Jyväskylä \\ Kokkola, Finland
}

\begin{abstract}
This study examines the development of the education model created in connection with the Master Studies in Mathematical Information Technology. The model has developed from the first stage, where there was only face-to-face teaching supported with Learning Management System, to a stage where studying is possible also fully in online and students may choose themselves how much to take advantage of technology in their studies. The examination of the development of the education model is made from the viewpoints of accessibility, increased role of technology and interaction. In earlier studies, the education model has been evaluated for example from the viewpoints of changes in the participation rate and learning results, and the results have been positive. These viewpoints, in addition to describing the development path, will be highlighted in this study.
\end{abstract}

Keywords—blended learning; distance education; accessibility

\section{INTRODUCTION}

Access to learning is one of the key factors in arranging education for adult students for example. Adult students have more external responsibilities, and as a result diversity among study participation modes is important. Blended learning environments are regarded as suitable solutions for this; at the same time, it is thought that they will preserve many positive aspects of traditional teaching [1]. With the help of the blended education model, it is possible to provide alternatives to participation modes such as faceto-face sessions which are time- and location-bound. However, to move from face-to-face study to the blended model often requires a long development trajectory where the development of technology plays a large role.

In blended learning, the learning environment integrates learning elements and processes as well as environments and interaction devices provided by information and communication technologies. Even though there are many definitions for blended learning, typically it is conceived as a combination of face-to-face learning and distance learning [2], [3]. Blended learning combines location- and time-bound activities with activities that are not dependent on location (e.g., real-time videos) and possibly not on time, either (e.g., on-demand videos). In connection with blended learning, one needs to pay attention also to the degree of integration, on the basis of which it is possible to evaluate the role of blended learning, and through that the role of technology, in learning.

Technology is at the centre of blended learning. Learning technologies enable arrangement of education in many different ways. However, typically these technologies themselves do not play the main role in the educational setting; the primary interest is, above all, on the practices formed around them. When developing an education model, the technologies available nevertheless define how far the development of the model can be carried.

Development work on solutions related to learning technologies has been going on for a considerable time with Master Studies in Mathematical Information Technology at Kokkola University Consortium Chydenius. The main aim is to develop an education model that will make education maximally accessible to all. At the same time, it is hoped that the developing educational model would give more choices for different kind of learners. To improve accessibility, technological solutions have been applied, more and more, in the implementation of educational solutions. As technology has become more widespread, also its role in the educational model has become emphasized. With the development of technology, it has been possible to carry the educational model forward in small steps over several years.

The current education model is based on strong utilization of streaming videos, the central role of the learning management system and reliable and cost-efficient practices formed around the technologies. The education model makes it possible to provide students with education in a way that makes it possible for them, in all organized teaching, to participate either face-toface, from distance with the help of real-time video or by using on-demand recordings during times more suitable for the student. The students have the freedom to select, for each lecture, the participation mode that is the most suitable for their life situation at the time. Once the accessibility of education has advanced this far, the student can define the degree of blended learning for him/herself.

The contribution of this study is to provide an overview and examples of how the educational model can be developed within the limits of technological development. The paper presents the development path of an education model created in connection with the Master Studies in Mathematical Information Technology at the Kokkola University Consortium Chydenius. During the development path, various technologies became blended to the teaching. Investigation is carried out especially from the perspectives of accessibility improvements, increase in the role of technologies and changes in interaction. The research also presents selected results from the evaluations carried out.

The paper is organized as follows: The following section takes a closer look at blended learning. Section III introduces the development path of the educational model formed in connection with the master's degree education in information technology. Section IV discusses the impacts of the blended 
educational model from the perspectives of blending, accessibility, interaction and learning outcomes. Section V presents some conclusions.

\section{BLENDED LEARNING}

Blended learning can take place in many different levels. Graham [2] defines four of them: activity level, course level, program level and institutional level. Blending at the institutional and program levels is typically left to the discretion of the learner. In the course and activity levels, designers and instructors do have a greater role when prescribing the blend. Activity level refers to situations where an individual learning activity includes both face-to-face and computer-mediated elements. As an example of this, we can consider a solution where interaction in a face-to-face course has been turned over to a computer to get help in its implementation, for example through LMS. In the course level blending, some of the course is arranged as face-to-face learning and some as distance learning with the help of a computer. These parts of the course can overlap time-wise or they can take place in a chronological order. The course level is the most typical level of blending. In higher educational institutions, blending often occurs at the level of a degree program [4]. This is referred to as program level blending. Typically, in the program level blended model, some of the courses are to be implemented as distance study and some as face-to-face study [2]. The choice between these may be based either on the decision of the student or that of the education provider. At the institutional level, the organization has made the decision concerning blending [2]. In these kinds of cases, blended parts can be found in all the organization's courses or, for example at the level of educational institutions, the decision might have been made to require that the graduating students must have experience about online courses [2]. When talking about institutional level blending, there is the realization that the organization must concentrate its attempts to reach a situation where the student can utilize the two extremes in his/her study [2].

Access to learning is one of the key factors influencing the growth of distributed learning environments [5]. In spite of this, research related to accessibility has been very meager in connection with blended learning [6]. From the viewpoint of accessibility, blended education can be arranged for many reasons. Picciano and Seaman [7] highlighted five of these aspects in their research: offering courses not otherwise available at the school, meeting the needs of specific groups of students, offering Advanced Placement or college-level courses, reducing scheduling conflicts for students and permitting students who failed a course to take it again. When making educational arrangements for adult students who have many responsibilities apart from family and work, there is an emphasis on reducing scheduling-related conflicts.

Whereas traditional instruction includes interaction between the student and the instructor in the same physical location, computer-mediated instruction employs solutions provided by information and communication technology to implement interactivity [8]. Interactivity thus is clearly different in these solutions. Graham [2] introduces 4 critical learning-related interaction dimensions (Fig. 1), which are present both in the traditional face-to-face environment and in the distributed learning environment. The dimensions are space, time, fidelity and humanities. At the two extremes of the dimensions are faceto-face learning and distance learning: the interactivity of the traditional face-to-face learning is located on the left hand side of the dimensions and the interactivity of the distance learning on the right hand side. The development of information and communication technologies has increasingly moved the interactivity in distance learning closer to the interactivity traditionally regarded as achievable only in face-to-face sessions. For example, on the time and fidelity dimensions, communication technologies such as real-time lecture videos and video conferences today allow real-time communication close to the same levels of fidelity as in the face-to-face environment [2]. Virtual solutions and, for example, tools made available in social media enable better team work among people, thus bringing the humanness dimension's extremes closer to each other. Virtual reality environments are striving to do the same with the space dimension.

The blended education model can also be categorized according to the way the blending takes place. Blended solutions can be classified into three categories in accordance with the main purpose of the blending [2], i.e., enabling blends, enhancing blends and transforming blends. In enabling blends, the primary focus is on addressing issues of access. This includes blends that are intended to provide additional flexibility to the learners and blends that attempt to provide the same opportunities or learning experience but through a different modality. In enhancing blends, some incremental but not radical changes to the pedagogy take place. For example, in traditional face-to-face environment, some additional resources may be included online. Transforming blends allows a radical transformation of the pedagogy. It should be kept in mind that a blended solution can belong to several categories at the same time. It is just as important to remember that none of these categories is necessarily bad; they just have a different focus [2].
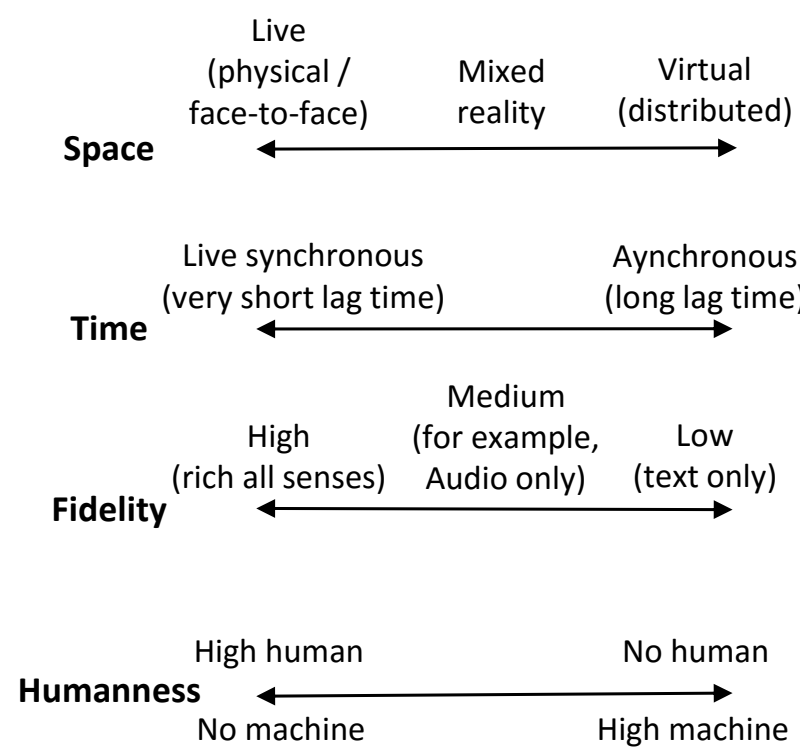

Fig. 1. Four dimensions of interaction in face-to-face and distributed learning environments by Graham [2] 
In general, one can think of the motivation for blending as something that combines the positive aspects of both face-toface learning and distance learning. Graham et al. [9], however, clarify this somewhat by claiming that blended education is there because it makes a better pedagogy possible, increases flexibility and contributes to cost-efficiency. The greatest interest in the environment of this study is directed into how to increase accessibility.

\section{DEVELOPMENT PATH}

The blended educational model formed in connection with the master's degree education in information technology has been under development, with a clearly defined purpose, since the beginning of 1999. The need for the development work has its origin in the fact that all the students in the education program are working adults with a family. The biggest challenges for students of this kind are related to time use. The time must be allocated between work, family and study. Thus, there has been a clear need to add flexibility to study participation. The central idea in the development work, from the very beginning, has been how to make the available teaching accessible so that the learning results wouldn't be weakened and teaching or studying wouldn't be made more difficult. The important part in the education development has been the desire to sustain the commitment to face-to-face learning. Some of the students still want to study with the help of face-to-face learning, and even students who in their studies utilize a variety of technologies participate mainly with the help of face-to-face learning in some courses. Moreover, face-to-face learning creates a natural production venue for lecture videos.

Already at the beginning stage of the development, it became clear that, at its best, the education model would make wellfunctioning distance study possible. However, the technologies and infrastructure in the beginning of the development work were not such that they would directly allow the start of the implementation of the model enabling distance study. Also high production costs posed challenges for wider deployment. Later, improvements in the technologies and related practices made it possible to develop the education model closer to the current implementation, where also distance study is possible, in line with the technology improvements.

This section presents the development stages that have led to the current kind of education model. The development steps are also shown in Fig.2.

\section{A. Stage 1: Beginning of Video Production}

In 1999, at the beginning of the master's degree course on information technology, all teaching was organized as face-toface teaching. Face-to-face learning was arranged mainly for Fridays and Saturdays. The courses were scheduled to be run as very compact entities in such a way that, typically, a single course was run over a few weekends. In practice, this meant that the duration of a single lecture session equaled that of 3-4 traditional lectures. In addition, intensive courses in which teaching was implemented as face-to-face teaching were organized over a period of one week. Typically, this meant 6-8hour lectures on each weekday. Students who were able to take time off from their work for a period of one week became participants of these kinds of courses.

Learning Management System (LSM) was in use from the beginning, and with its help targeted communication and dissemination of information became possible. It also provided an easy access for the students to written study materials. In addition to using LMS internally within the courses, it was used, already at that stage, for student management and communication between the students and the education provider. This kind of communication was related to study, exam enrolments, exam results and changes to course schedules, among other things. For the use of LNS, the students were required to have an internet connection, but the connection speed required was very low. This kind of modest connection was already available, either in the workplace or at home, for each student in the education program.

The challenges of adult students' time allocation forced the education provider to look for an alternative solution for

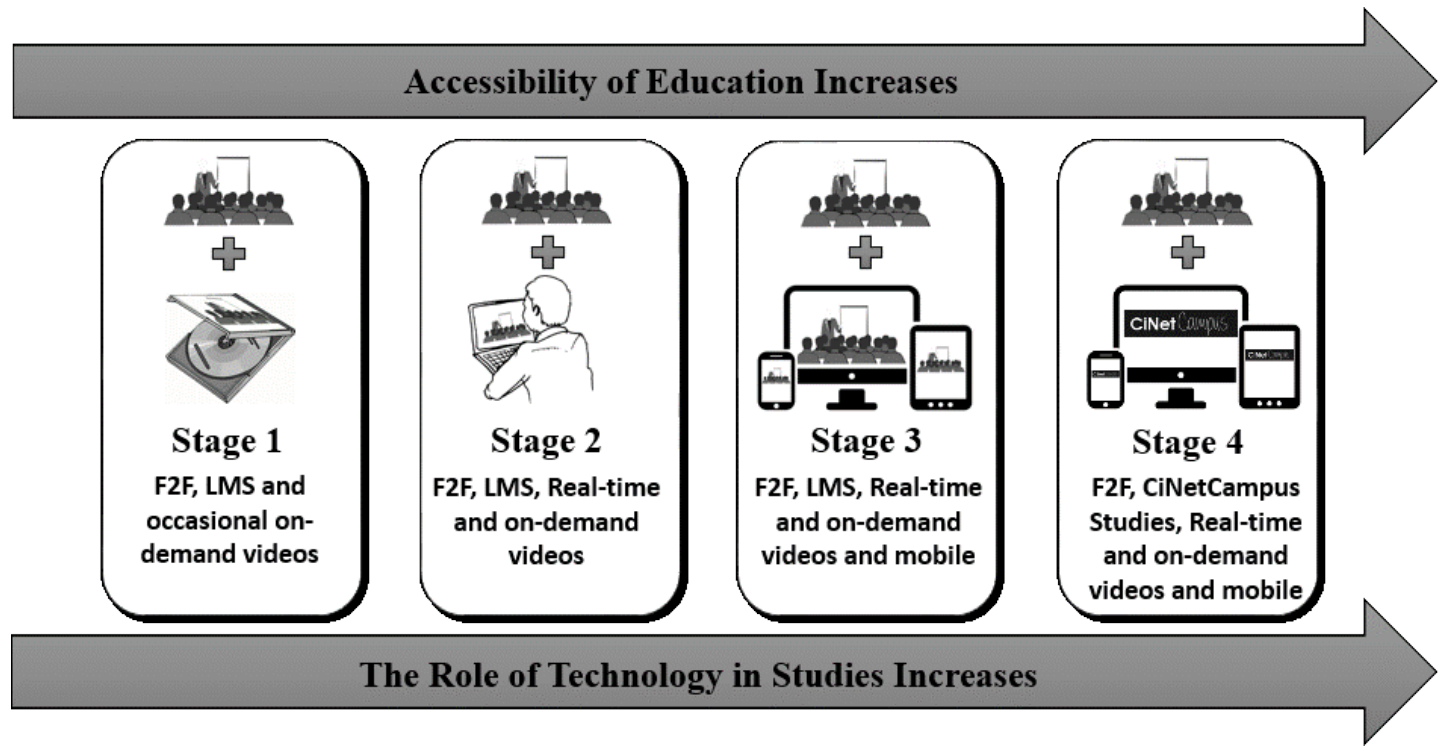

Fig. 2 Technological development stages 
situations where the student occasionally is not able to participate in a face-to-face teaching session. Even one-off absences in very compactly arranged courses made the completion of the courses considerably more difficult. The situation was even worse in intensive courses. For example, an illness could mean losing the face-to-face study opportunities for the whole course, in which case the only thing was to substitute these with the written course material.

Lecture video production was piloted as a solution for this problem. The production process used required many man-hours at that time. In practice, a person recording the video was present, and often there was also a person to look after the marking of the time stamps needed for the synchronization of teaching material and video. Post-production for the video, which required a lot of human resources, was carried out after the recording. Video, audio and the material presented during the lecture were synchronized with the help of the collected time stamps. The learning material created in this way became a pedagogically well-functioning whole, and its technical quality was very good. However, the production process was so cumbersome and expensive that it was possible to produce videos only for some individual courses.

Already at this stage, the videos were stored in the media server, but the students' data connections were not yet sufficient for the transfer of videos through the network. Therefore, the only solution for the distribution was the use of CD-ROM (and at the later stage DVD) diskettes; the videos for a single course required more than $10 \mathrm{CD}$-ROM's storage space. From the viewpoint of the education provider, the distribution process was a real challenge to manage cost-efficiently. The videos were produced in the Real Media format for the reasons related to their production. This somewhat limited the hardware configurations that could be used for watching the videos.

Due to the slowness of the production process, the CD-ROM diskettes containing the course videos were completed only after the course was over. Thus they were of hardly any benefit to the students taking the course. In the best of cases, the videos could be used for revision before the exam at the end of the course. The videos were used to some degree mainly for self-study during the second time the course was run. As a matter of fact, the video production process piloted at this development stage and the pilot videos did not play any significant role in relation to the blending and accessibility of teaching.

\section{B. Stage 2: Video Lectures Alongside with Face-to-Face}

The production of videos in the manner explained above wasn't an adequate solution from the perspective of accessibility. Videos had to be produced considerably faster and in the extent of the whole education program to be able to see any improvement in the accessibility of education. From the perspective of accessibility and study schedule, in addition to ondemand videos, there was also need for real-time transmission of lecture sessions.

Improvements in production processes, new technologies and infrastructure such as faster data communications enabled the move to lecture videos produced in streaming formats and to the development of production- and distribution-related processes which were lighter than previously. The use of streaming videos made transmissions of real-time videos beside on-demand videos possible. By 2005, the production and distribution processes had improved to become so light that the production could cover the whole education offer for the master's program. The important thing in making the production processes lighter was the growth of automation. For example, recording was automated so that it could be done without the presence of a camera operator. There were still many work stages which were related to the preparation stage and the editing stage and required human input. The production was made more efficient also by beginning to equip the teaching premises with integral technological solutions. The teaching premises were designed to allow a natural integration of technologies to lecture halls, technologies such as the microphone and camera solutions and other equipment required in recording

To make the production process lighter, it was also necessary to do away with the person recording the video and give up postediting, where the image, audio and study material were synchronized into a combined whole. This was reflected in the quality of the material produced. When the lecture material is no more integrated with presentation, more attention must be paid to the recording in a live teaching situation. Without a person to record the video and without equipment capable of controlling image selection, it wasn't possible to get, on a good quality video, all the lecture material presented in the location. Recording of material written on the whiteboard was an especially challenging task. To find a solution to this, various sensor-based solutions to switch between image sources were developed for the premises. During the latter part of the development stage, a solution was settled upon: the image source for videos was captured from the image input to the video projector. At this stage, the lecturers proceeded to use the whiteboard instead of the document camera. In this way, all the study material shown by the video projector in the lecturer's space could be seen, in a very good quality, on the video. The image capture from the image input of the data projector onto the video was a considerable step forward from the perspective of the cost-efficiency of the production process, video quality and, through that, video usability.

At that stage, lecture videos were offered as streaming videos in the Windows Media and Real Media formats. Naturally this made video viewing dependent on the browser and equipment. Already at that time, almost all students in Finland had some kind of Internet connection available also at home. Data connection bandwidths were also sufficient for the video distribution to be realized through a media server. This made the distribution process significantly lighter. However, it should be kept in mind that, as far as the image quality and image size were concerned, compromises had to be made to make the video suitable to students' still modest data connections.

The links to the media server were provided with the help of LMS. In LMS, each course has its own work space, the membership of which consists only of the students on that course. The links to lecture videos were distributed through these course-specific work spaces. In many education solutions, this is still today a common way to distribute video material to students. In addition, this video technology incorporated its own user management. In this way, videos could be confined only for the 
use of the students of the course in question, which was very important from the viewpoint of copyright-related problems.

Nonetheless, there were still many challenges related to video production. Even though the production of videos already had a fairly reliable basis, there were still some process stages that made them prone to human errors. For example, linking videos to LMS, which was done manually, made it liable for suffering from writing errors. Moreover, the production process undergoing continuous technological development was susceptible for malfunctions of the new devices. The solution applied was not an optimal substitute for teaching situations where interaction played a major role, either. These kinds of situations included seminar-type lectures, which expect strong participation from the student. The technologies and formats employed and solutions related to user management, among other things, affected equipment support, limiting that support considerably. In practice, to play the videos, a PC with the Windows operating system and a suitable video player were required.

At this stage, however, study participation with lecture videos was not yet offered to the students as a solution enabling distance study but as a supplementary alternative for situations where participation in face-to-face learning was impossible for one reason or another.

Lecture videos enable distance study and relocate the study, to a certain degree, to take place farther away from the campus area. This means that new needs that are emerging advocate moving many activities that traditionally have occurred in the campus area to the web. For most of the students, the need to visit the campus is reduced due to LMS and lecture videos. In addition, face-to-face learning is arranged mainly for evenings and weekends, at the time when the office staff is not present. Physical encounters, for example for the purpose of study instruction, are often difficult to arrange in education that is organized in this way. For this reason, the degree program deployed a separate web conferencing software enabling distance guidance and also developed practices related to it. Each member of the teaching personnel participating in the supervision of the degree program was given an individual virtual office linked to the software. The virtual office could be used for the purpose of supervision, as required, and it could be equipped with online tools designed to suit optimally to any use situation.

\section{Stage 3: Distance Learning Becomes Possible}

The most important challenges for the next development stage were improvements to be made to accessibility by expanding the equipment support, improvements to video quality, automation to be carried even further and improvements to be made in operational reliability.

Better device independence in video production was achieved by moving to the use of the h.264 video format beside Windows Media. This allowed watching the videos also with mobile equipment. In practice, the deployment of h.264 meant using two parallel encoders when producing streaming video. Therefore, also automation had to be expanded to deal with two simultaneous video productions of the same lecture. The videos were still distributed to students by linking them through LMS.
The quality of videos could be improved in line with the increase in the speed of data communications and with new HDlevel technologies. Production of videos with various levels of quality also started. This made it possible to select the quality of a video in accordance with the equipment used for watching it or in accordance with the bandwidth allocated for it. This of course required, among other things, an increase in the disk space in the server application.

Constant attention to automation still played a central role in making the production lighter. Automation was a framework condition for all development work. It was necessary, as far as possible, to automate the practices formed around the technological solutions to be deployed. At this development stage, the transfer of video files to the server was automated and timed. Also, in addition to the implementation of video on- and off-switching, tools for carrying out central automation of recordings were created. Remote equipment control also reduced the resources required for recording. The costs of video production were, in practice, insignificant. Videos could be produced of all courses for each run of the course in question.

Automation also significantly reduced production uncertainties due to human factors. Reliability was naturally increased by the experience gained from the technologies and the practices formed around them. According to research, the production at this stage was very reliable: during 2008-2010, the success rate was approximately $99 \%$, and in 2011 it was already about $99.4 \%$ [10].

Faster broadband connections for the students and improvement in technologies and the practices formed around them finally made it feasible to provide education also purely as distance study. The teaching provided at this stage was thus accessible in practice by all devices and, thanks to mobile connections, also in a location-independent manner. Highquality, reliable and easily accessible teaching in the form of videos meant for the student that he/she could, at will, substitute face-to-face learning wholly with lecture videos. This made it a learning environment which is accessible to students regardless of time or place, which supports asynchronous or synchronous interactivity and which blends to the student's daily life to become a part of it.

The lighter production process and the coverage of the video production made it possible to provide teaching over several weekdays in smaller packages. Up to that point, it had been necessary to arrange teaching in compact blocks of several hours in length to provide, to some extent at least, realistic opportunities for working students to participate in study with the help of face-to-face learning or real-time video. On the other hand, large video packages had made the production of lecture videos easier. As the production became lighter, there was no more any need for that. Now the study could be split into smaller blocks, and the students could participate in it with the help of video if they couldn't be present at face-to-face sessions. The change that took place in the timing of face-to-face learning was helped also by that the increased role of videos in study participation reduced the number of those attending face-to-face sessions. Those who participated in face-to-face learning were mainly students for whom the actual time of learning had no significance from the viewpoint of participation. 


\section{Stage 4. Virtual Campus}

Studying with the help of videos differs from study with the help of traditional face-to-face teaching. The biggest differences are, naturally, related to interactivity. The traditional video player used did not provide any kind of interaction channel from the student to the lecturer. Studying with the help of videos also created a challenge to the formation of groups among the students. In the previous solution, distance students were not visible in a lecture situation. Both the lecturer as well as the faceto-face students were unaware of their presence. Making the presence of distance students visible could help in the formation of groups and would motivate the lecturer to pay more attention to those students.

The aim of the next development stage was to increase opportunities for interaction, make possible learning situations where interaction plays an important role and help the lecturers' chances to attend students studying with the help of lecture videos. At the same time, the aim was also to lighten the user management related to video viewing. At this development stage, there was a clear move from the improvement in accessibility to making the distance learning more relevant. The solution consisted of a video sharing module, which was suitable for watching videos, on an open source-code multimedia platform. The multimedia platform is WWW-based and provides support also for mobile devices. Thus videos can always be accessed through an internet connection. This is important to ensure that the learning environment of the degree program is as easily accessible as possible.

The video sharing module replaced the traditional media player, which the students had used up to that point for watching videos. Built in this module was an interaction channel from the student to the teacher to support study with real-time video. This channel had not been a part of the earlier solutions. The interaction channel was implemented with the help of text-based chat. With the help of the module, students can also see the other video viewers and communicate with them.

Similarly, in face-to-face learning sessions, it is possible to see who are attending the lecture with the help of videos. For face-to-face learning situations, the platform features a built-in Lecturer's View, as it is called. With the help of this view, the profiles of all the students who have logged in into the video application to watch a real-time video about the teaching situation in question are displayed. In addition to the participants' images, a chat-based interaction channel is thus shown in the lecturer's view. In a face-to-face teaching situation, the view to the module is realized by projecting the lecturer's view, in a sufficiently large size, to the back wall of the teaching area with the help of a data projector. This allows the lecturer to keep track of the students participating with the help of video and of the messages sent by them. The lecturer can do this in a natural manner, without moving his/her eyes away from the face-to-face students. Also a module collecting attendance figures in the classroom was integrated into the platform. With the help of it, the face-to-face students could mark themselves as being present. This also allows the distance students to see in the video sharing module who are attending the face-to-face session. The solution had the aim to help students to form groups and allow the lecturer to better observe the students studying with the help of lecture videos.

From the student's viewpoint, increasing opportunities for interactivity and grouping significantly altered the participation with the help of videos. The Lecturer's View module brought a change also to the lecturer's work. It allows the lecturer to see who are attending with the help of video and makes it possible also to communicate with them.

The text-based interaction channel of the video sharing module is, naturally, unsuitable for example for seminar-style study where each student in turn presents his/her work to the other participants in the seminar. For this purpose, so-called Video Chat was introduced. Video Chat was created with the help of a commercial video conferencing software. Video Chat enables real-time video-based communication and file sharing. Thus it is well suited for teaching situations where interactivity is required. The web conferencing software used earlier for study supervision was replaced with this same Video Chat module. The use of Video Chat does not, in any way, limit the recording of the teaching situation in accordance with the prevailing practices.

LMS, which was used earlier already, the video sharing module, the Lecture View module and Video Chat were integrated into an as seamless whole as possible, into a virtual learning environment called CiNetCampus Studies. Other modules such as Survey Tools and the Learning Style module were integrated into the same whole. CiNetCampus Studies forms a kind of virtual campus where the student can easily choose the mode to access the teaching provided. In this way, also the use of videos is integrated as a natural part to the existing learning environment. The integration of LMS as a part of the virtual campus also made the centralized management of user rights possible. User management is taken care of with LMS's tools and is automatically transferred to the use of the modules forming the CiNetCampus Studies. With the help of the user rights the video sharing module has received, it can restrict the student's access only to the correct lecture videos of a study course. The joint user management of the CiNetCampus Studies has significantly reduced the amount of work. Previously, distribution of the rights for lecture videos was carried out with the help of the Kokkola University Consortium's Active Directory, and it was kept separate from the courses' user rights in LMS. This caused management overlap and error situations due to information flow problems, which can be avoided in the new solution. In future, the CiNetCampus Studies learning environment will enable the incorporation of many kinds of functionalities for example to activate the distance student.

\section{EFFECTS}

The improvement of the education model has had hardly any effect on the work of the teacher. In fact, except for the last few years, the transparency of the solution to the lecturer has been one of the goals of the development work. As a consequence of video recording, the lecturer has been forced to switch from the use of the whiteboard to the document camera. Otherwise, there has been no attempt to restrict the work of the teacher or presentation materials in any way. Neither has the lecturer been given the responsibility for example for starting or ending the recording of videos. 
Lecture videos of the face-to-face learning are produced with very limited human resources. For the education provider, the education model has, in practice, incurred only the cost of buying the equipment, which is very modest and one-off.

The biggest impact from the improvement of the education model has been on the student. The increasing role of technology, that is, the blending of technology to learning as a part of it and to study, and, through that, increasing accessibility are significant changes from the viewpoint of many students. It is also quite clear that, due to the increase in the role of technology, the way of study itself has changed. The biggest changes are related to interaction and grouping, which are more challenging to implement in the blended model education.

On the other hand, there have been many positive changes in the education organized in that way. The student can pace his/her study in the way desired, participate in the study when feeling alert, take advantage of revision in the study and study in one's own peace when it seems convenient. Besides giving support to accessibility, the provision of various participation alternatives enables support also to students with different study preferences. One important added value offered by videos is naturally the possibility for revision. Videos can be used for revision, regardless of the initial way of participation. It is understandable that the education in accordance with the blended model has also impacted the students' learning results. This section examines the blending of technology into study as a part of it, increase in accessibility and the effects of the education model on interaction and learning results.

\section{A. Blending}

In the educational practice that developed in connection with the master's degree education in information technology, the student can decide about the degree of his/her own blending. The student can participate in each lecture of a study course in many different ways by flexibly combining various alternatives. The more the student takes advantage of the technologies provided as aids for learning the more blended will his/her study be and vice versa. Here the degree of blending refers to the importance of the role that technological solutions have from the student's perspective. In extreme circumstances, the student can keep studying without blending, either as a face-to-face student or as a distance student completely supported by lecture videos. However, here we should keep in mind that even students who are engaged in face-to-face learning are compelled to use some technologies. This is due, among other things, to management of communication and distribution of materials through LMS.

The educational development steps that are the subject of this research can be examined in relation to the Graham's [2] levels of blending presented above. The first stage was still quite close to traditional face-to-face learning. The education model included, however, some activity level blending. Transfer of some individual learning activities for implementation with the help of certain technologies took place. These kinds of activities included provision of learning material and communication outside lectures. The latter was implemented with the help of LMS. This kind of activity level blending with the help of LMS occurred at each stage.
Stage 1, piloting of video production, didn't yet enable blended learning during the course under way because the videos became available to the students only after the course had ended. At a later stage, the videos were used, to a certain extent, as selfstudy material. It is possible to think of that as the course or program level blending, depending on whether the videos were used as substitutes for individual lectures or for whole courses. The use of videos for this purpose wasn't very extensive, however.

From Stage 2 onwards, we are clearly talking about institutional stage blending. The provider of education was consciously aiming to focus on a situation where all matter taught could be studied by both extremes and also by combining these extremes in multifarious ways. One should remember that in the education model under scrutiny the student can decide about the degree of blending of his/her studies for each lecture and adapt them to his/her desires as far as blending is concerned. The student can blend a part of his/her own study on a course level defined by Graham by completing some of the course through distance learning and some of it as face-to-face learning. The decision in the area of education discussed here is made by the student and not by the teacher. On the other hand, the student can blend his/her own study on the program level by completing some of the courses wholly through distance learning and some wholly as face-to-face learning.

In its current form, the education model contains, for some courses, also new features of activity level blending. For example, in seminar courses some students give a presentation with the help of video conferencing, using the video chat function. Seen through the eyes of a student engaged in face-toface learning, activity level blending takes place during the course.

If we examine the way of blending from the viewpoint of Graham's [2] three blending categories, we may state that the original aim had been to make learning more accessible in accordance with the Enabling Blends category and offer distant participants more or less the same learning experience as provided for those who participate in face-to-face learning. One of the goals of the development work has been, specifically, to make the solution transparent to the lecturer. Nevertheless, with the advance of the development work, once accessibility has reached an adequate level, it has been possible to move the focus closer to the Transforming Blends category, where it is possible to look for completely new pedagogical ways for teaching. This is emphasized especially at Stage 4 of the development, where the focus has been on building a learning environment which supports various kinds of pedagogical solutions.

In the education program under research, studying in accordance with the blended model is thus the student's own choice. One could, therefore, assume that the extent to which the technologies are utilized indicates that the model is approved by students. The distribution of participation through face-to-face learning and with the help of lecture videos has been investigated in the previous research [10]. The investigation showed that the utilization of the technologies for participation in education plays a fairly important role. As we can see in Fig.3, approximately two-thirds of participation takes place with the help of real-time or on-demand video. We may, therefore, 
assume that the students themselves regard blended learning as suitable for their needs.

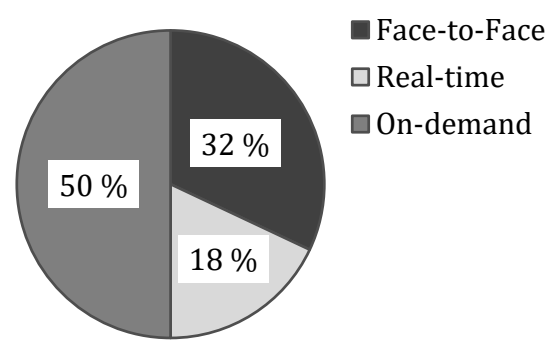

Fig. 3. Relative shares of participation modes of all lecture participations 2008-2011 $(n=2988)$ [10].

Blending of technologies into normal study as parts of it has been helped by the solutions used becoming more commonplace. Smart phones, tablets and for example viewing videos online are today familiar things to almost everyone. For example, the emergence of YouTube (launched in 2005) occurred almost at the same time as the increasing use of videos in teaching was taking place. If the technologies are those that the student would use in his/her life in any case, their role and importance in learning will naturally not be emphasized to such an extent as when we are dealing with dedicated learning technologies.

\section{B. Accessibility}

When arranging education for the needs of specific group like adult working students, among the motivations for increasing accessibility, as presented above by Picciano and Seaman [7], the emphasis is on the reduction of scheduling conflicts. Lecture videos, of course, also provide the course lectures for review for students who did not pass the course.

The accessibility of the education examined in this publication has increased along with the development allowed by the technologies presented above. During the first development stage, accessibility increased, above all, with the help of LMS, from where the students could get the lecture materials. The students' only option was to participate in face-toface learning. The education was thus still very time- and location-bound from the perspective of accessibility. At the beginning of lecture video production, not all of the offer of the education program could be covered, and the video distribution took place in such a late stage that it didn't have much impact on accessibility.

For students who possessed suitable equipment and a sufficiently fast Internet connection, the second development stage was easy to access already. To a quite considerable degree, students like these could select at which time they wanted to study. They were still location-bound, however: PCs were used for distance study because there was no support yet for mobile equipment. Nevertheless, face-to-face learning still played a major role, and lecture videos were being used, above all, for reviewing.

The increase in location- and device-independence and the increased production reliability brought by the third development stage were important as far as the improvement in the accessibility to education was concerned. After this, the students could quite freely and in accordance with their own wishes choose where and when to study.

The fourth development stage improved accessibility mainly for learning situations where physical presence was required in the past. Situations of this kind included for example a seminar where the student had to make a presentation of some kind. The solutions of the earlier development stages did not make the student's own presentation possible because the interaction channel was text-based. At the fourth development stage, the video chat integrated into the learning environment made it possible. Similarly, the video chat brought a new and better tool for instruction and supervision. Generally, the fourth development stage made distance learning more relevant and lecture videos more practical as learning tools.

The improved education accessibility achieved with the help of various technologies now means, in practice, that students can participate in the degree program education in many different ways. The students do not need to decide about their participation mode beforehand; they can choose to participate in each lecture the way that suits best for their life situation or study preferences.

Research [11] has shown that before video recording started in 2005, the participation rate in face-to-face learning was about $54 \%$. The poor participation rate is explained by that the students at that time were working adult students and education is offered only as face-to-face teaching. Once all study was offered also in the form of video, the participation rate grew by $70 \%$. However, when we look at Fig.3, it becomes clear that participation in faceto-face learning has decreased.

\section{Interaction}

Interaction in education along the lines of the blended model is very different from that in a pure face-to-face learning solution. The four dimensions of interaction presented by Graham [2] describe the critical components of interaction very well. The dimensions are shown in more detail in Fig.1. Technological developments have brought the interactivity of the face-to-face situations (on the left hand side of the dimensions) closer to the interactivity of distance learning (on the right hand side of the dimensions).

At the first development stage of the environment under study, learning was still biased towards face-to-face sessions. In practice, the students participated in study with the help of faceto-face lectures. Some of the activities had been transferred for the implementation of LMS. At this stage, the situation was that the interactivity of the face-to-face learning was indeed located at the dimensions' left end and, when utilizing the technologies, at the dimensions' right end.

Starting from the second stage of the development, distance learning was based, to a large extent, on videos, either in the form of lecture videos or in the form of a video conference in instruction situations. When studying with the help of videos it is possible to reach close to the same levels of fidelity as in the face-to-face environment. Already from the beginning of the second stage, the student could participate not only with ondemand video but also with real-time video. Thus, communication from the teacher to the student became 
synchronized on the time dimension. The absence of a return channel from the student to the teacher in lecture videos however made the interaction completely one-way, and in this sense it was very different from the interaction in face-to-face learning. Communication that took place outside face-to-face learning was managed through LMS, which automatically gave it very asynchronous characteristics. The web conferencing software that was used in some learning situations provided then real-time interaction to both directions.

The CiNetCampus Studies learning environment created during the fourth development stage significantly improved the interaction. A chat-based return channel was created for videos: first as text-based and later also aided by real-time video conferencing. The text-based chat is used in all learning and the video chat, for the time being, is used in learning situations such as seminars, which require interactivity. The CiNetCampus Studies also includes elements such as the Lecturer's View, with which the intention is to engage distance students better with the face-to-face space. We may assume then that there has been convergence also on the space dimension, even though actual mixed reality environments have not been developed. Considering the interaction of the Humanness dimension, it is likely that the solutions, for example the video chat work spaces made available to the students, that improve team work among the students in the CiNetCampus Studies environment also bring the extreme ends of the dimension closer to each other.

Here we should emphasize that face-to-face learning has been a part of all the development stages in the education model. The students have thus had opportunities for mutual interaction within that framework. During the first two development stages, participation in face-to-face learning was clearly prioritized. Later there has been a change in the priorities: participation has taken place more and more as distance learning with the help of technologies. Already at the beginning stage, the challenges related to time use created a situation that made participation in face-to-face learning difficult in practice. This is evidenced by the $50 \%$ participation rate in 2005 . Thus, in practice, in half of the cases it wasn't possible to make use of the available interaction in face-to-face learning. Coming to Stage 4, study participation emphasized participation with the help of videos to such a degree that it was seen necessary to provide distance students with better interaction opportunities with the help of technologies.

\section{Learning Outcomes}

When the impacts of the blended education model from the viewpoint of learning outcomes were examined in a research [12], it was found that the students who utilized equally both face-to-face learning and videos participated in the study more than others and they also passed the courses better than the others. Students who mainly utilized videos had a better participation rate as well as a better course-completion rate than students who mainly made use of face-to-face learning.

The investigation also took the grading perspective into account. When students participating principally through faceto-face learning were compared with students participating mainly with the help of videos, it was found that the students aided by videos got on average better grades. In spite of their better participation rate, students who evenly utilized both participation modes received slightly worse grades than the others.

When the motives for the selection of participation mode were looked at in a further investigation [13], it was pointed out that among the students who utilized both participation modes there were many students who would have liked to participate in face-to-face learning but who, for practical reasons, used videos in study participation from time to time. They thus studied partially contrary to their learning preferences. This may, to some extent, explain their grades that were lower than the grades of other students. However, it seems that this has had no effect on passing a course.

On the other hand, a research [14] that examined study participation times found that students who participate with the help of videos at the pace of face-to-face learning - that is, viewing the videos usually before the next lecture - achieved better learning outcomes than students who studied completely at their own pace without paying attention to the scheduling or pacing of the face-to-face learning.

Increasing accessibility thus increases the rate of participation, which has a positive effect on learning outcomes. However, learning outcomes suffer if flexibility is misused and studying is moved to take place too near to the end of the course, in which case there is the possibility that too much information in too short a time must be absorbed.

\section{CONCLUSIONS}

Technological development has enabled the staged development of the blended education model in connection with the Master Studies in Mathematical Information Technology at the Kokkola University Consortium Chydenius. The solution is aimed, above all, to improve accessibility to learning. Improvement in accessibility has corresponded to the growth in the role of technology as a part of study.

In the current model, the student can decide about the degree of blending, as far as his/her own study is concerned, by utilizing the available technological solutions in the way desired. On the one hand, with the help of technology, studying from distance only is perfectly possible, but, on the other hand, it is also possible to study with the support of a completely isolated faceto-face setting, in which case LMS is the only technology that the student has to use.

Some sub-areas of the education model developed have been evaluated from many viewpoints in earlier research. According to research, technological solutions blend well to the study as parts of it. This is evidenced for example by that students have taken them extensively into use. Study with the help of lecture videos has come to play an important role in environments resembling the one in this research.

In education, in accordance with the blended model presented above, the concept of being present or attending is, naturally, completely different from the same concept in education where students participate only in face-to-face study. With the passing of years, the degree of participation in face-toface study has decreased, but the improved accessibility has, on the whole, led to increased study participation. 
Interactivity is, of course, different and challenging to implement in education in line with the blended model. Technology has, however, made the convergence of the better aspects of distance learning and face-to-face learning possible when looked at from the viewpoint of interactivity.

Although the education model under investigation enables distance learning, just a very small group of students studies only from distance. Similarly, the group of students who solely use face-to-face learning is very small. In the environment where the student has the freedom to choose his/her way to learn, most of the students have chosen a model that is blended on some level. Based on the learning results, the students who study in blended mode do not suffer because of their study mode. Rather, the improved participation rate achieved with the help of various technologies has led to better learning results

It's been stated that future learning systems will be differentiated not based on whether they blend but rather by how they blend [4]. The Stages 2 and 3 of the development in the environment under study might be thought as displaying the typical current status of most of the education solutions that are in accordance with the blended model based on lecture videos. With the development of technology, also educational models will improve. We may be justified to think that this kind of education model won't be ready ever.

\section{ACKNOWLEDGMENT}

The research for this paper was financially supported by European Social Fund, grant no. S20073, without which the present study could not have been completed. The authors wish to thank the Central Finland Centre for Economic Development, Transport and the Environment for their help.

\section{REFERENCES}

[1] B. Collis, H. Bruijstens, and J. Veen, "Course redesign for blended learning: modern optics for technical professionals", Int. Journal of Continuing Engineering Education and Lifelong Learning, vol. 13, no. 12, 2003.
[2] C.R. Graham, "Blended learning systems: definition, current trends and future directions", In Handbook of blended learning: Global perspectives, local designs, C. J. Bonk and C. R. Graham, Eds. San Fracisco: Pfeiffer Publishing, 2006, pp. 3-21.

[3] C. D. Dziuban, J. L. Hartman, and P. D. Moskal, "Blended learning", EDUCAUSE Center for Applied Research, Research Bulletin, vol. 2004, no. 7, 2004.

[4] B. Ross and K. Gage, "Global perspectives on blending learning: insight from WebCT and our customers in higher education", In Handbook of blended learning: Global perspectives, local designs, C. J. Bonk and C. R. Graham, Eds. San Fracisco: Pfeiffer Publishing, 2006, pp.152-155.

[5] C. J Bonk, T. Olson, R. A. Wisher, and K. L. Orvis, "Learning from focus groups: An examination of blended learning", Journal of Distance Education, vol. 17, no. 3, pp. 97-118, 2002

[6] C. R. Graham, "Emerging practice and research in blended learning", In Handbookof distance education, 3rd ed., M. G. Moore, Ed. New York, NY: Routledge, 2013, pp. 333-350.

[7] A. G. Picciano and J. Seaman, K-12 online learning: A survey of U.S. school district administrators. Needham, MA: Sloan Consortium, 2007.

[8] C.R. Graham and C. Dziuban, "Blended learning environments", In Handbook of Research on Educational Communications and Technology, 3rd ed., J. Spector, M. Merrill, J. Merrienboer, and M. Driscoll, Eds. New York: Taylor \& Francis, 2008, pp. 269-274.

[9] C. R. Graham, S. Allen, and D. Ure, "Benefits and challenges of blended learning environments", In Encyclopedia of information science and technology, M. Khosrow-Pour, Ed. Hershey, PA: Idea Group, 2005, pp.253-259.

[10] M. Myllymäki, J. Penttilä, and I. Hakala, "Producing lecture videos from face-to-face teaching", Int. Journal of Information and Education Technology, vol. 4, no. 1, pp.18-24, 2014.

[11] M. Myllymäki and I. Hakala, "Video-based blended learning practice in master studies", In The proceedings of Iasted international conference web-based education, V. Uskov, Ed. Acta Press, 2013, pp. 872-878.

[12] I. Hakala and M. Myllymäki, "The use of lecture videos: attendance and student performance", In Proc. 14th International Conference on Computers and Advanced Technology in Education, V. Uskov, Ed. Galgary, IASTED, ACTA-PRESS, 2011.

[13] M. Myllymäki and I. Hakala, "choosing a study mode in blended learning”, In Proc. Ann. Conf. Innovation \& Technology in Computer Science Education, Goldweber, \& Goelman, Eds. USA: ACM, 2012, pp. 291-296.

[14] M. Myllymäki and I. Hakala, "Temporal differences in participation modes in video-based blended learning practice", In Proc. Int. Conf. EDULEARN14 Education and New Learning Technologies, L. Gómez Chova, A. López Martínez, and I. Candel Torres, Eds. Barcelona: IATED Academy, 2014, pp.2000-2006. 